\title{
Isolation, identification and molecular characterization of virulent avian infectious bronchitis virus in Khyber Pakhtunkhwa, Pakistan
}

\author{
Shabina ${ }^{1}$, Sarzameen ${ }^{2}$, Shams ul Hayat ${ }^{3}$, Saira Gul ${ }^{1}$, Saleha Gul ${ }^{4}$, \\ Haseena ${ }^{5}$ and Attaullah ${ }^{4 *}$ \\ 1. College of Veterinary Sciences and Animal Husbandry, Abdul Wali khan University, Mardan-Pakistan \\ 2. Department of Poultry Science, Faculty of Animal Husbandry and Veterinary Sciences, the University of \\ Agriculture, Peshawar-Pakistan \\ 3. Veterinary Research and Disease Investigation Centre, Kohat-Pakistan \\ 4. Department of Zoology Islamia College Peshawar-Pakistan \\ 5. Institute of Biotechnology and Genetic Engineering, The University of Agriculture, Peshawar-Pakistan \\ *Corresponding author's email: attakhan_154@yahoo.com \\ Citation
}

Shabina, Sarzameen, Shams ul Hayat, Saira Gul, Saleha Gul, Haseena and Attaullah. Isolation, identification and molecular characterization of virulent avian infectious bronchitis virus in Khyber Pakhtunkhwa, Pakistan. Pure and Applied Biology. Vol. 7, Issue 2, pp435-442. http://dx.doi.org/10.19045/bspab.2018.70054

\begin{tabular}{llll}
\hline \hline Received: 16/12/2017 & Revised: 24/03/2018 & Accepted: 28/03/2018 & Online First: 31/03/2018 \\
\hline
\end{tabular}

\section{Abstract}

Infectious bronchitis virus (IBV) of the Corona viridae family is a single stranded RNA virus; a causative agent of respiratory and urogenital tract diseases in chickens. This pathogen causes huge economic losses throughout the world where chickens are produced for commercial purposes. Embryonated egg inoculation was used for detection and amplification of IBV RNA, (specific pathogen free) SPF eggs ( $n=50,9-11$ days old) were inoculated with IBV suspected samples. After incubating the eggs for 72-144hours, the infectious allantoic fluids were harvested when signs of curling, stunting, dwarfing and death of the embryos appeared after inoculation. Viral RNA used in the RT-PCR was extracted from virus containing allantoic fluid and reverse transcribed to cDNA for detection of IBV and their serotypes. PCR products were electrophoresed to visualize the results. A high percentage $(36 / 50$ eggs $)$ of the eggs $(P<0.05)$ were found infected with the virus in embryonic cells. The main necrotic lesions caused by the IBV in eggs were curling, stunting, dwarfing and mortality. First round PCR showed 75\% samples were positive for IBV, whereas second round PCR confirmed $77.77 \%$ samples were positive for the Massachusetts serotype. In summary, despite of vaccination against IBV, this viral pathogen still circulates in Khyber Pukhtunkhwa. In addition, Massachusetts serotype is emerging with new variants leading to vaccine failure.

Keywords: Curling; Embryonated eggs; Infectious bronchitis disease; Massachusetts; Poultry; RT-PCR

\section{Introduction}

Avian Infectious Bronchitis disease (AIB) is an acute viral respiratory disorder of poultry with high contagious nature. The disease mainly attacks the respiratory tract and causes inflammation of the bronchi, reproductive disorders and nephritis. Clinical signs vary based on the age of birds, pathogenicity of the virus strain and existing level of immunity [1,2]. In broilers (2-6 weeks) the main clinical signs of IBV are difficulty in breathing, tracheal rales, 
coughing and sneezing with or without nasal discharge, weakness accompanied by depression, reduced feed consumption and body weight loss [3]. The nephritic form of IBV is characterized by mild and transient respiratory signs followed by depression, ruffled feathers, hunched stance, reluctance to move, excessive water intake, rapid weight loss and diarrhea [3]. In reproductive form, many flocks show a decline in egg production associated with eggs of smaller size and inferior external and internal quality such as eggs softness, pale-shelled with thin albumen [4]. IBV incidence was first reported in 1931 in USA in a group of young chickens [5]. From that time, the malady has been recognized in layers, breeder and broiler chickens worldwide. IBV has a considerable economic impact with a high mortality rate (25-60\%) in infected flocks. Poor weight gain, mortality, sub-optimal and down grading of eggs production leads to significant losses in the poultry industry [6]. The serological differences between the vaccine strains and the strain that causes the infection are responsible for the frequent epidemics of IBV [7]. Different IBV serotypes in Asia are Mass, Conn, Gray, Ark 99,793/B-India, NRZ-China, HVChina, and A1121-Taiwan [8]. The post translational changes within the IBV spike protein lead to the formation of $\mathrm{S} 1$ and $\mathrm{S} 2$ subunits [9]. The changes in the nucleotide sequence of $\mathrm{S} 1$ are said to be responsible for the appearance of variants which cannot be effectually controlled by various vaccines. Among IBV proteins, the $S$ protein and its subunit $\mathrm{S} 1$ are the most variable and key inducer of defensive immunity [10]. Poultry industry, with an investment of Rs 732 billion and with an annual growth rate of $10-12 \%$, is one of the most vibrant segments of the agriculture sector of Pakistan (Eco, survey of Pak, 2013-2014 [11]. Studies conducted at the molecular level on IBV in KP, Pakistan are scant therefore, the present study aimed to characterize IBV from allontoic fluids of embryonated eggs and investigate its genotyping, serotyping and protectotyping.

\section{Material and methods}

\section{Sample collection and virus isolation}

This study was carried out on commercial chickens at Department of Poultry Science, Faculty of Animal Husbandry and Veterinary Sciences Peshawar, Khyber Pakhtoonkhwa Pakistan. Trachea, lungs and kidneys samples were collected aseptically from the post mortem section where birds died due to suspected IBV outbreaks, brought from the commercial chicken flocks across different parts of Khyber Pakhtoonkhwa Pakistan. Pooled $20 \%$ tissue suspensions were inoculated intra-allantoically into 9-11 day-old embryonated chicken eggs to observe the dwarfing, curling and death of embryos and the allantoic fluid was then harvested and used for RNA extraction as shown in the plate 1 .

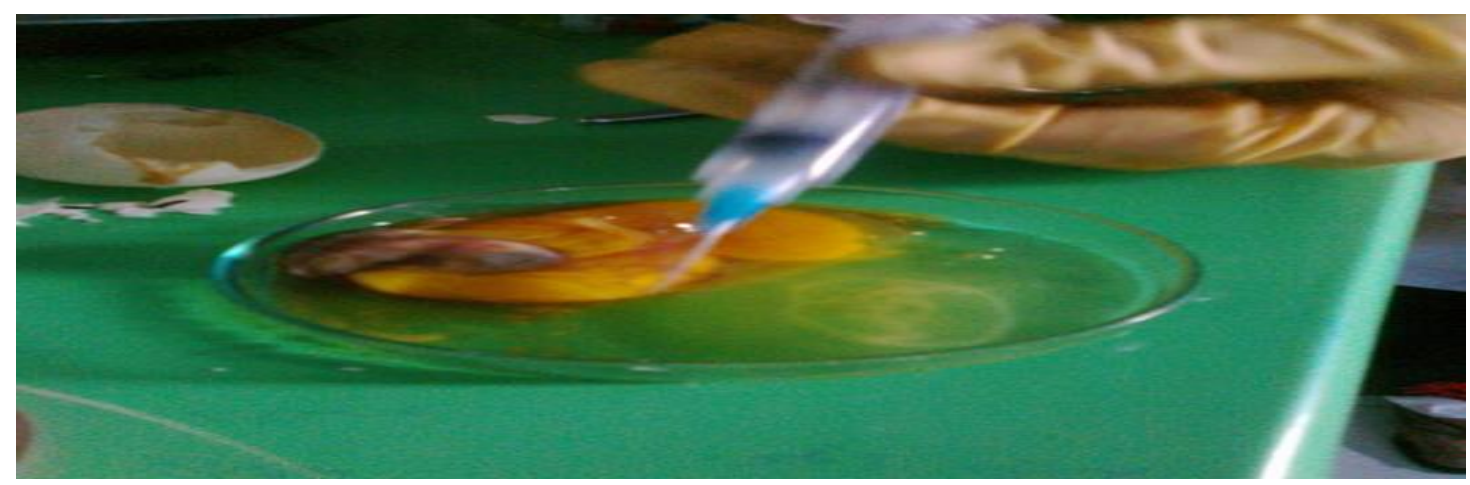

\section{Plate 1. Collection of allontoic fluids as harvest for RNA extraction}

\section{RNA extraction and RT-PCR}

The entire egg samples positive on inoculation were used for RNA extraction.
For each sample, two eppendorf tubes were used. Primers were diluted at $10 \mathrm{X}$ with RNAs free water. RNA was extracted 
according to (Norgen) KIT procedure. In each tube $6 \mu$ l of RNA carrier was taken. RL Solution was added to all the tubes in amount of $600 \mu 1$.After that $150 \mu 1$ of each sample was added to all the tubes containing mixture respectively. Pulse vortexing of all tubes was carried out 20 times. All the tubes were incubated at 15$25^{\circ} \mathrm{C}$ for $10 \mathrm{~min}$.

The tubes were then centrifuged $4000 \mathrm{rpm}$ for 10 minutes and $600 \mu 1$ of ethanol was added to all the tubes. Again pulse vortexing was done and the tubes were briefly centrifuged $5000 \mathrm{rpm}$ for 15 minutes. An amount of $700 \mu$ l of the total mixture was moved to the columns inserted in the collection tubes and then centrifuged at $10,000 \mathrm{xg}$ for $60 \mathrm{sec}$. The flow through in the tubes was removed and the columns were reinserted into new collection tubes. Now $700 \mu \mathrm{l}$ of washing solution W1 was added to all the tubes and centrifuged at $10,000 \mathrm{xg}$ for $1 \mathrm{~min}$. The tube containing flow through was discarded and the columns were inserted into new collection tubes. W2 solution $(700 \mu \mathrm{l})$ was added to all the columns and again centrifuged at 10,000 rpm for $1 \mathrm{~min}$. The tubes containing the remaining fluid were disposed off and the columns were placed into new collection tubes.

The tubes were then centrifuged at 14,000 rpm for 30 second. The spin columns were then shifted to $1.5 \mathrm{ml}$ collection tubes. Sol E $50 \mu 1$ was added to all the tubes and then placed at room temperature for incubation for 3 mins. The tubes were then centrifuged at $14,000 \mathrm{rpm}$ for $1 \mathrm{~min}$. At the end the spin columns were discarded and the elute in the micro centrifuge tubes containing viral RNA was collected. The collected RNA was directly used in RT-PCR application. Extracted RNA was screened for the presence of IBV by using nested RT-PCR. Briefly $10 \mu \mathrm{l}$ of template RNA, $2 \mu \mathrm{l}$ of dNTPs, with $1 \mu$ l of Random primer (ER) were mixed together and poured into a 0.2 $\mathrm{ml}$ of PCR tube. After cooling $4 \mu \mathrm{l}$ of $10 \mathrm{x}$ RT-Buffer and $1 \mu \mathrm{l}$ reverse transcriptase enzyme (Thermoscientific, USA) was added. Time set and incubation temperature was $10 \mathrm{~min}$ at $25^{\circ} \mathrm{C}, 60 \mathrm{~min}$ at $42^{\circ} \mathrm{C}$ and 5 min at $85^{\circ} \mathrm{C}$ as described earlier [12]. The first amplification reaction was carried out with one-step RT-PCR using the general pair of primer, BVEF (5-CACTGGTAATTTTTCAGATGG-3) and IBVER

(5-CCTCTATAAACACCTTTACA-3).

The second amplification reaction was carried out using the specific sets of primers, IBVD

(5TTCCAATTATATCAAACCAGC-3), IBVM

(5-AATACTACTTTTACGTTACAC-3) and IBV4

(5-AGTAGTTTTGTGTATAAACCA-3).

Thermal conditions for PCR reaction were; initial denaturation at $94^{\circ} \mathrm{C}$ for $3 \mathrm{~min}, 30$ cycles of $94^{\circ} \mathrm{C}$ for $30 \mathrm{sec}, 55^{\circ} \mathrm{C}$ for $1 \mathrm{~min}$, $72^{\circ} \mathrm{C}$ for $1 \mathrm{~min}$ and a final extension at $72^{\circ} \mathrm{C}$ for $7 \mathrm{~min}$. The same thermal conditions were used for second round PCR.

\section{Gel electrophoresis}

Amplified PCR products were run over 2\% Agarose gel. Various bands corresponding to different IBV serotypes were visualized using an ultraviolet gel documentation system (Uvitec Limited, Cambridge, UK).

\section{Statistical analysis}

The data was statistically analyzed through using SPSS software (SPSS, Inc., Chicago, IL, USA). (SPSS, Inc., Chicago, IL, USA). The variables were compared using a chisquare test. $P<0.05$ was perceived as statistically significant.

\section{Results}

\section{Replication of virus in embryonated eggs}

After 72-144 hrs of incubation the (pathological signs) curling and death of embryos was observed in eggs. The main necrotic lesions caused by the IBV in these eggs were curling, stunting, dwarfing and mortality. These were the strongest signs sufficient to judge the multiplication of the virus in the embryonated eggs. Out of 50 eggs 28 were found with these signs which constitute $56 \%$ of the sample size, while in 8 eggs only death of the embryos was caused which constitute $16 \%$ of the sample 
size with no specific signs and were considered as less positive as described in table 1 . On the other hand the lesions were not observed in those eggs which were either rotten or with no embryo formation which might be affected by some incubation factors i. e incubation temperature, humidity and turning frequency. A higher percentage $(P<0.05)$ was found in 36 eggs as a result of virus replication in the embryonic cells as shown in the table 2. The pool harvested from positive eggs was used for virus isolation and RNA extraction.

Table 1. Egg Inoculation of tissue samples

\begin{tabular}{|c|c|c|c|c|}
\hline $\begin{array}{c}\text { 9-11 days old } \\
\text { embryonated eggs }\end{array}$ & No. & $\begin{array}{c}\text { Candling time after } \\
\text { inoculation }\end{array}$ & $\begin{array}{c}\text { Positivity/ } \\
\text { negativity }\end{array}$ & \%age \\
\hline $\begin{array}{c}\text { Dead embryos( Dwarfism, } \\
\text { stunting, curling) }\end{array}$ & 28 & $5-6$ days & ++ & $56 \%$ \\
\hline Dead embryos & 8 & $2-3$ days & + & $16 \%$ \\
\hline Rotten eggs & 3 & $2-3$ days & - & $6 \%$ \\
\hline No embryo at all & 4 & 1 day & -- & $8 \%$ \\
\hline Unidentified signs & 7 & 5-6days & - & $14 \%$ \\
\hline Total & 50 & & & $100 \%$ \\
\hline
\end{tabular}

Table 2. Presence of infectious bronchitis virus on RT-PCR

\begin{tabular}{|c|c|c|}
\hline Samples & No. & Percentage\% \\
\hline Positive & 27 & 75.00 \\
\hline Negative & 9 & 25.00 \\
\hline Total & 36 & 100 \\
\hline $\boldsymbol{P}<\mathbf{0 . 0 5}$ & & \\
\hline
\end{tabular}

\section{$1^{\text {st }}$ Round PCR}

To amplify the nucleotide sequence of IB virus, the process was carried out with the help of a set of general primers. Amplification of 27 samples of 466bp showed that RT-PCR was performed correctly. It also proved the presence of IBV in the samples as shown in (Figure 1).

\section{$2^{\text {nd }}$ Round PCR}

The $1^{\text {st }}$ round PCR positive 27 samples on $2^{\text {nd }}$ round PCR showed that among the three serotypes only Massachusetts serotype was identified in 21 samples attaining a band size of approximately $297 \mathrm{bp}$ while the remaining samples were unidentified as shown in the figure 2 .

The table 3 shows the presence of mass serotype in 21 samples out of 27 . This was confirmed by 2 nd round PCR. It was also confirmed that IBV infection in poultry is caused by mass serotype which is prevalent in this region. Second round PCR specified the prevalent serotype.

\section{Discussion}

Infectious bronchitis is one of the most important and common infectious diseases of respiratory system of chickens [13]. In the concerned study 50 different samples originating from suspected cases at postmortem section Veterinary Research Institute, Peshawar were selected for isolation of virus and molecular characterization. The present study was aimed at investigating the isolation of infectious bronchitis virus from allontoic fluids of embryonated eggs and its genotyping followed by propagation of the virus as vaccine strain. Table 1 shows that on inoculation of samples in 9-11 days old embryonated eggs, $72 \%$ of total eggs were positive $(P<0.05)$ while $28 \%$ of eggs give negative results.56\% of the positive findings were strongly positive while the remaining were said to be less positive based on macroscopic lesion. Similar results were found ( $79 \%$ positive) for IBV 
by the real-time assay [14]. It was suggested in one of the research work that a range of strains of IBV could be detected in the allantoic fluid obtained from chick embryos after inoculation [15]. The results showed by Jahantigh [12] are supporting our current study as 4 out of $11(36.36 \%)$ of the sampled flocks were positive to IBV by RT-PCR. The specific nested PCR performed on RT-PCR positive flocks proved that the circulating serotype of infectious bronchitis virus in Zabol was Massachusetts which is further assisting our results. On the other hand the results described by Wang et al., (1998) [16] prove that RT-PCR require a number of individual steps for the identification of different serotypes which make it time consuming and cumbersome. The lesions on embryo caused by IBV after sample inoculation are usually observed within 5-7 days but are not pathognomonic for IBV spotting [1]. RT-PCR was applied on RNA extracted from the suspected tissue samples and allontoic fluids. This technique has proved to be very efficient in identifying the IBV and different serotypes of IBV [15].

Table 3. Detection of Mass serotype on Nested-PCR $2^{\text {nd }}$ round

\begin{tabular}{|c|c|c|}
\hline Samples & No. & Percentage\% \\
\hline Positive & 21 & 77.77 \\
\hline Negative & 6 & 22.22 \\
\hline Total & 27 & 100 \\
\hline $\boldsymbol{P}<\mathbf{0 . 0 5}$ & & \\
\hline
\end{tabular}

In the present study Real time PCR on 36 positive samples showed the presence of IBV in the region. It was confirmed through molecular study that 27 samples $(75 \%)$ were amplified to $466 \mathrm{bp}$ which is a clear evidence of the presence of IBV in this region as shown in the figure 1 . On the basis of statistical analysis $(P<0.05)$, it was confirmed that infection has been circulating in the region which need further molecular study. Before 1956 it was observed that a single genotype is the causative agent of IBV acquisition however it was confirmed later that virus originates in different serotypes due to antigenic variations [17]. Previously, a total of 945 serum samples were analyzed in Pakistan and three IBV strains (Connecticut, M-41, Arkansas) were reported [18]. It was further analyzed from $2^{\text {nd }}$ round PCR that present infection of IB is caused by the serotype that is prevalent in this area as shown in the figure 2. The product run on gel electrophoresis identified 21 samples of 297bp $(P<0.05)$ which showed that the current infection is caused by the Massachusetts serotype. The same serotype is responsible for heavy loss in poultry industry due to the havoc caused by this virus. The remaining 6 samples were unidentified which may be a sign of new variants having different genotype and change nucleotide sequence. Jahantigh et al. conducted a work to identify the infectious bronchitis virus with groupspecific primers in Zabol, south-east of Iran. Their results showed that $36.36 \%$ of the sampled flocks were positive to IBV by RT-PCR [19]. It has been studied that any minor change in the nucleotide sequence of $S$ protein interfere with the effect of vaccine which ultimately results in vaccine failure and leads to usual IBV outburst [20]. Vaccines that contain serotypes which differ in its antigenic and genotypic characters from the confront virus can cause better protection [21]. One possible clarification of the vaccination failure is the continuous emergence of new strains and serotypes of IBV [22]. Antigenic characterization of IBV isolates is important for selecting new and appropriate vaccines for the corresponding geographical regions [23]. In summary, 
despite of available vaccine, IBV infection is still wide spread in KP, Pakistan. In addition, Massachusetts serotype is new emerging IBV variant leading to vaccine failure.

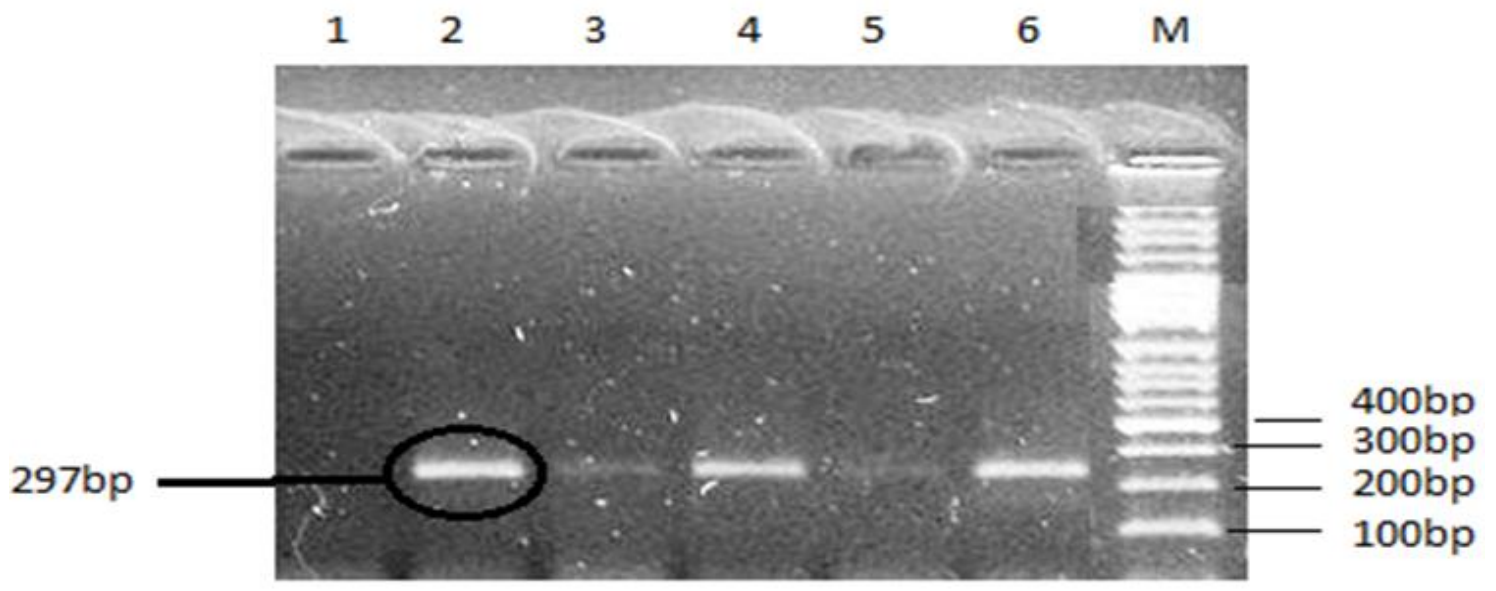

M: 100bp DNA Ladder Samples 1,3,5 are Untypeable, Sample $2,4,6$ are Genotype MASS.

Figure 1. Detection of IBV in different samples using RT-PCR

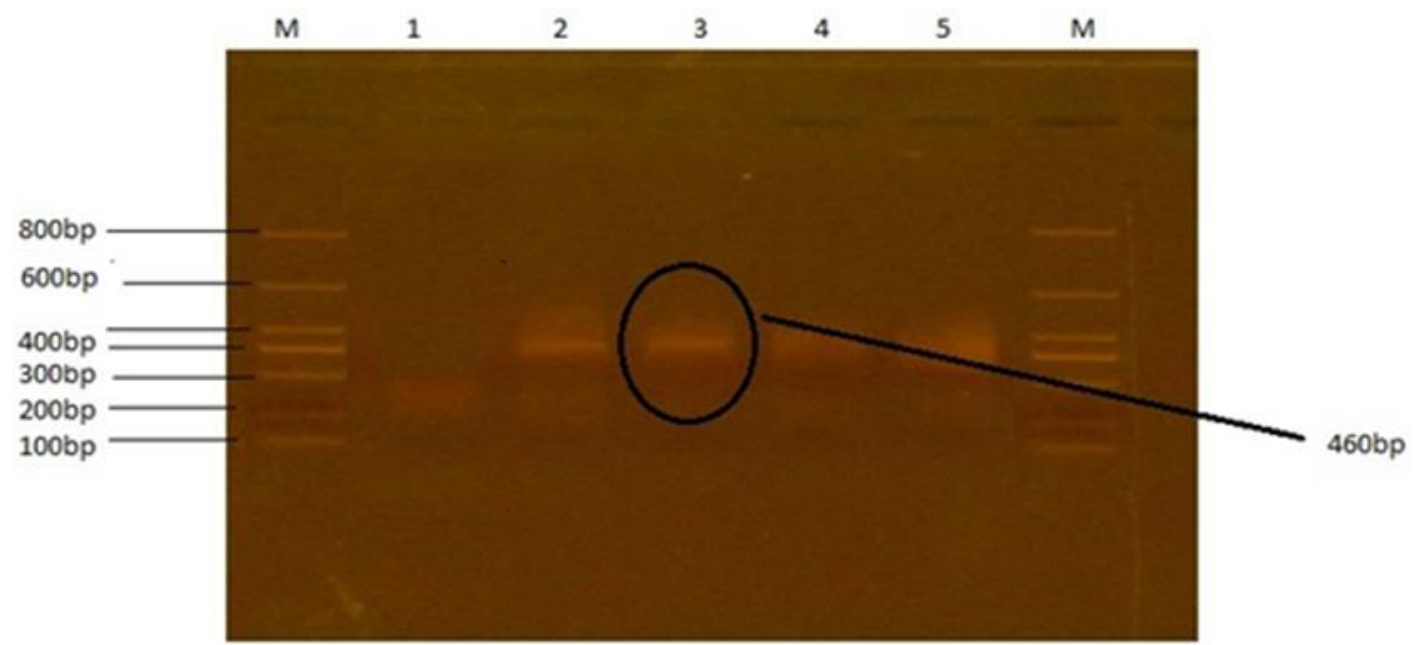

M: DNA Ladder $100 \mathrm{bp}$, sample 1 is negative and samples 2,3,4,5 are positive

Figure 2. Presence of Massachusetts genotype showed on gel electrophoresis

\section{Authors' contributions}

Conceived and designed the experiments: Shabina, Sarzameen \& SU Hayat, Performed the experiments: Shabina, Analyzed the data: Attaullah, Contributed materials/ analysis/ tools: S Gul, S Gul \& Haseena, Wrote the paper: Attaullah.

\section{Acknowledgement}

This research was supported by the Higher Education Commission, Pakistan.

\section{References}

1. Mcmartin DA, Mcferran JB \& Mcnultym S (1993). Infectious bronchitis virus infections of birds. Elsevier Sci Publishers, Amsterdam 4: 249-274.

2. Cavanagh D, Davis PJ \& Cook JKA (1992). Infectious bronchitis virus: evidence for recombination within the 
massachusetts serotype. Avian Pathology 21: 401-408.

3. Cumming RB (1963). Infectious avian nephrosis (uremia) in Australia. Australians Veterinary J 39: 145-147.

4. Sevoian M \& Levine PP (1957). Effects of infectious bronchitis on the reproductive tracts, egg production, and egg quality of laying chickens. Avian Diseases 1: 136-164.

5. Hitchner SB, Winterfield RW \& Appleton GS (1966). Infectious bronchitis types in the United States. Avian Diseases 10: 98-102.

6. Bisgaard M (1976). Influence of infectious bronchitis virus on egg production, fertility, hatchability and mortality rate in chickens. $J$ of Veterinary Medicine 28: 368-376.

7. Gelb JJ, Wolff JB \& Moran CA (1991). Variant serotypes of infectious bronchitis vims isolated from commercial layer and broiler chickens. Avian Diseases 35: 82-87.

8. Wit JJ, Jka, Cook \& Vanderheijden HMJF (2010). Infectious bronchitis virus in Asia, Africa, Australia and Latin America-history, current situation and control measures. Workshop: infectious bronchitis (ib) in the Brazilian poultry industry 12(2): 97-106.

9. Boursnell ME, Brown TD, Foulds IJ, Green PF, Tomley FM \& Binns MM (1987). Completion of the sequence of the genome of the coronavirus avian infectious bronchitis virus. $J$ of General Virology 68: 57-77.

10. Cavanagh D (1995). The coronavirus surface glycoprotein. in: siddell SG. The coronaviridae. New York: Plenum73-113,

11. Economic survey of pak (2013-2014). Economic advisor's wing, agriculture, ministry of finance government of Pakistan, Islamabad, Pakistan.

12. Jahantigh $M$, Saeed $S$ \& Mahdi $H$ (2013). Detection of infectious bronchitis virus serotypes by reverse transcription polymerase chain reaction in broiler chickens. Springer Plus 2: 36.

13. Cavanagh D, Naqi S, Saif YM, Barnes HJ, Glisson JR, Fadly AM, Mcdougald \& Swayne DE. (2003). Infectious bronchitis, in Diseases of poultry, Iowa, 11th edition, Ames, Iowa state university press, pp. 101-119.

14. Callison SA, Hilt DA, Boynton TO, Sample BF, Robison R, Swayne DE \& Jack WM (2006). Development and evaluation of a real-time taqman rt-pcr assay for the detection of infectious bronchitis virus from infected chickens. J of virol Methods 138(1-2): 5-60.

15. Handberg K, Nielsen OL \& Pedersen MW (1999). Detection and strain differentiation of infectious bronchitis virus in tracheal tissues from experimentally infected chickens by reverse transcription-polymerase chain reaction. Comparison with an immune histochemical technique. J of Avian Pathology. 4(28): 327-335.

16. Wang $\mathrm{CH}$, Hsieh MC \& Chang PC (1998). Isolation, pathogenicity, and h120 protection efficacy of infectious bronchitis viruses isolated in Taiwan. Avian Diseases 40: 620-625.

17. Estola $\mathrm{T}$ (1966). Studies on the infectious bronchitis virus of chickens isolated in finland with reference to the serological survey of its occurrence. Acta Veterinaria Scandinavica, Supplementum x8, pp 1.

18. Muneer MA, Newman JA \& Goyal AM (1987). Antibodies to avian infectious bronchitis virus in Pakistani chickens. Poultry Sci 1(66): 765-767.

19. Jahantigh M, Salari S \& Hedayati M (2013). Detection of infectious bronchitis virus serotypes by reverse transcription polymerase chain reaction in broiler chickens. Springer Plus 2(1): 36.

20. Ma FL, Fu XL, Cheng Z, Jiasy, Chenr M, Liu WS \& Xuan H (2004). The isolation identification and experimental vaccination of infectious 
bronchitis virus causing proventriculitis. J of Veterinary Sci 24: 225-227.

21. Cook JKA (1984). The classification of new serotypes of infectious bronchitis virus isolated from poultry flocks in Britain between 1981 and 1983. Avi Path 13: 733-41.

22. Zongxi Han, CS, Baolong Y, Xiaonan $\mathrm{Z}, \mathrm{Yu} \mathrm{W}$, Chengren L, Qingxia Z, Yazhen M, Yuhao S, Qiaoran L,
Xiangang K \& Shengwang LA (2011). 15-year analysis of molecular epidemiology of avian infectious bronchitis coronavirus in China. Infection Genetics and Evolution 11: 190-200.

23. De Wit JJ \& Cook JK (2014). Factors influencing the outcome of infectious bronchitis vaccination and challenge experiments. Avian Pathol 43: 485497. 